\title{
Structure and Air-Oxidation Behavior of the Isotropic Pitch-Based Carbon Fiber
}

by

\author{
Junya MIZUNO*, Masakazu MORIMOTO*, Noriko NONO** and Toshiaki SOGABE*
}

Structure and air-oxidation behavior of the isotropic pitch-based carbon fiber were investigated. The carbon fiber was heat-treated with various temperatures in the range from 1000 to $2500^{\circ} \mathrm{C}$ under argon gas atmosphere. Lattice constant $d_{002}$ of the carbon fiber obtained by powder X-ray diffraction analysis was significantly reduced by the heat-treatment from 1500 to $2000^{\circ} \mathrm{C}$. The crystallite sizes of the carbon fiber $L_{c}(002)$ and $L_{a}(110)$ were only $3 \mathrm{~nm}$ even after heat-treatment with $2000 \sim 2500^{\circ} \mathrm{C}$. While the carbon fibers heat-treated with 1000 and $1500^{\circ} \mathrm{C}$ showed broad peaks of D- and G-bands in Raman spectra, those peaks became sharp after heat-treatment with more than $2000^{\circ} \mathrm{C}$. It was observed by thermogravimetry (TG) that both air-oxidation starting temperature of the carbon fiber and activation energy of the oxidation reaction became higher as the increase of heat-treatment temperature of the carbon fiber. In the air-oxidation test which was carried out at $550^{\circ} \mathrm{C}$ under stagnant air, the carbon fiber heat-treated with $1000^{\circ} \mathrm{C}$ lost its weight by $35 \%$ for 1 hour since starting the test. On the other hand, the carbon fibers heat-treated with 2000 and $2500^{\circ} \mathrm{C}$ only lost their weights less than $0.1 \%$ for 1 hour since starting the test. After 3 hours from the start of the test, the rates of weight loss of the carbon fibers heat-treated with 2000 and $2500^{\circ} \mathrm{C}$ increased about 5 times compared with that of initial 1 hour. It may be noticed that new active points in the carbon fiber were created by air-oxidation and these newly created points accelerated the air-oxidation reaction. For the carbon fibers heat-treated with 2000 and $2500^{\circ} \mathrm{C}$, much higher peaks of D-band in Raman spectra were observed after $10 \%$ weight loss than those of before air-oxidation, and these findings are probably due to the newly created active points.

\section{Key words:}

Carbon fiber, Isotropic pitch-based, Heat-treatment temperature, Structure, Raman spectra, Air-oxidation, Activation energy, Active point

\section{1 緒 言}

等方性ピッチ系炭素繊維は, 等方性ピッチを溶融紡系 により繊維化したのち, 熱処理して得られる. 原料であ る等方性ピッチは, 石炭や石油の残椬油から得られ, 縮 合芳香環またはそれらがアルキル結合などにより連結し た分子または分子の集団が, 無秩序に配向しているため に光学的に等方性である. 従って, 等方性ピッチ系炭素 繊維は, 炭素六角網平面から構成される結晶子があまり 発達しておらず，またその配向性が低い1)，そのため等 方性ピッチ系炭素繊維は, PAN 系などの他の炭素繊維に 比べて機械的強度や弾性率が低いものの, 熱や電気を通 しにくく，また適度な硬さを有していることから，高温 炉用断熱材や摺動部材の添加剂として広く利用されてい る $^{2)-6)}$.
而酸化特性に代表される炭素繊維の活性ガスとの反応 性は製品ライフに影響する重要な因子である. 高温炉に 使用されている断熱材がシリコンやサファイアの結晶成 長工程において炉内の酸素種をはじめとする各種ガスに より劣化することが報告されている ${ }^{5)}$. また, 摺動部材 での摺動特性は炭素繊維の酸化挙動の解析が重要となる. 炭素繊維の而酸化特性は結晶構造や表面状態, 金属不純 物などに影響されるが，等方性ピッチ系炭素繊維につい てこれらの詳細な報告は, ほとんどなされていない. そ こで本研究では, 石炭由来の等方性ピッチを炭素前駆体 とする等方性ピッチ系炭素繊維の構造および空気酸化挙 動を調べた. 特に, その炭素繊維の熱処理温度の違いに よる構造変化が与える酸化耐久性への影響について検討 した.

$\dagger$ 原稿受理 平成 27 年 9 月 16 日 Received Sep.16, 2015 C2016 The Society of Materials Science, Japan

* 大阪ガスケミカル(株) C F 材料事業部 研究開発部 $=554-0051$ 大阪市此花区西島

Research \& Development Dept., Carbon Fiber Materials Business Div., Osaka Gas Chemicals Co.,Ltd., Konohana-ku, Osaka 554-0051

** 大阪ガスケミカル侏) フロンティアマテリアル研究所 $=554-0051$ 大阪市此花区西島

Frontier Materials Labolatories, Osaka Gas Chemicals Co.,Ltd., Konohana-ku, Osaka 554-0051 


\section{2 実験}

\section{1 供試材}

大阪ガスケミカル株製のドナカーボ®ミルド品（平均 繊維直径 $13 \mu \mathrm{m}$, 平均繊維長 $0.11 \mathrm{~mm}$ ）を用いた。これを 誘導加熱炉を用いてアルゴンガス雰囲気中で 1000〜 $2500^{\circ} \mathrm{C}$ の熱処理（保持時間 2 時間）をおこない，それぞ れ熱処理温度の異なる炭素繊維サンプルを調製した。

\section{2 観察および構造解析}

炭素繊維の観察には KEYENCE 製の走査型電子顕微鏡 VE-8800 を用いた。加速電圧は $2 \mathrm{kV}$ とした。また，炭素 繊維の結晶構造を調べるためにラマン分光法（DXR Raman Microscope、Thermo Fischer 製) およびX 線回折 法（Mini Flex II，Rigaku 製）を用いた．ラマン分光法は出 力 $2 \mathrm{~mW}$, 波長 $532 \mathrm{~nm}$ のレーザー光をビーム径 $2 \mu \mathrm{m}$ に絞 つて測定をおこなった．X 線回折法では炭素繊維の粉末 $\mathrm{X}$ 線回折図形から学振法を用いて ${ }^{7), 8)}$ 黒鉛の結晶パラメ 一タを算出した。なお, 回折図形の解析には Carbon Analyzer Version 4.10D を用いた ${ }^{9)}$. また，炭素繊維の開気 孔構造はガス吸着法を用いて調べた。測定は，マイクロ トラック・ベル社の BELSORP-max を使用し $\mathrm{N}_{2}$ 吸着 $(77 \mathrm{~K}$ ) でおこなった。

\section{$2 \cdot 3$ 熱分析}

炭素繊維の空気酸化挙動を調べるために示差熱天㷏 TG-DTA（TG8120, Rigaku 製）を用いた。炭素繊維のサン プル約 $10 \mathrm{mg}$ を白金パンにいれ，空気 $100 \mathrm{ml} / \mathrm{min}$ を流した 状態で昇温速度 $5^{\circ} \mathrm{C} / \mathrm{min}$ で室温から $1000^{\circ} \mathrm{C}$ ま゙加熱し, そのときの重量変化を測定した。また，反応速度論解析 として小沢法 ${ }^{10)}$ を用いた。この方法では 3 種類以上の昇 温速度で測定した TG データから, サンプルの空気酸化 反応における活性化エネルギーを求めることができる. TG 測定において昇温速度を大きくするにつれて TG 曲 線は高温側へシフトしていくが，このシフト量は測定サ ンプルの分解反応における活性化エネルギーに依存する 今回は，1つのサンプルに対して 4 種類の昇温速度 $\left(5^{\circ} \mathrm{C}\right.$ $/ \mathrm{min}, 10^{\circ} \mathrm{C} / \mathrm{min}, 15^{\circ} \mathrm{C} / \mathrm{min}$ および $20^{\circ} \mathrm{C} / \mathrm{min}$ ) で $\mathrm{TG}$ 測定を おこない, これらの TG 曲線群から一定の減量率を示す 温度を求めた. その温度の逆数に対して昇温速度の対数 をプロットすると一定の変化率において直線関係が得ら れ, 下記の小沢の式(1)より直線の傾きから活性化エネル ギーを求めた。

$$
\log \beta=\log \frac{A E}{g(\alpha)}-2.315-0.4567 \frac{E}{R T}
$$

$(\beta$ : 昇温速度, $A$ : 頻度因子, $g(\alpha)$ : 反応速度式, $E$ : 活 性化エネルギー, $R:$ 気体定数)

\section{$2 \cdot 4$ 酸化消耗試験}

炭素繊維を一定温度の空気酸化䨌囲気に保持したとき の重量減少の挙動を調べるために酸化消耗試験をおこな った. 磁性皿に炭素繊維を $5 \mathrm{~g}$ 程度入れ，これを空気が停 滞している $550^{\circ} \mathrm{C}$ に保持された電気炉 (熱電工業(株社製) 内に投入した。これを $0.5 \sim 1$ 時間の間隔で電気炉から取
り出し，炭素纎維の重量変化を測定した.

\section{3 結果と考察}

\section{1 炭素瀻維の結晶構造}

Fig. 1 に $1000^{\circ} \mathrm{C}, 1500^{\circ} \mathrm{C}, 2000^{\circ} \mathrm{C}$ よび $2500^{\circ} \mathrm{C}$ で熱処理 された炭素㵶維の電子顕微鏡（SEM）写真を示す. 何れ の炭素繊維についても確認できる欠陥はなく, かつ側面 および断面は滑らかであった。このような平滑な表面で あるのは, 結晶子の選択的な配向性がないことによると 考えられる. また, 䋊維の直径についても熱処理温度に よる変化は認められなかった。
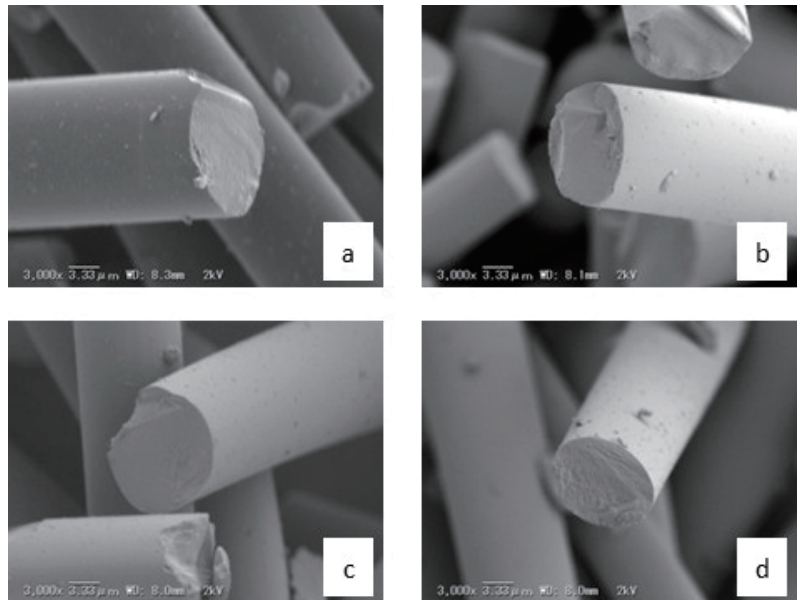

Fig. 1 SEM micrographs of the isotropic pitch-based carbon fibers treated with various heat-treatment temperatures (HTTs). (a: HTT $1000^{\circ} \mathrm{C}$, b: HTT $1500^{\circ} \mathrm{C}$, c: HTT $2000^{\circ} \mathrm{C}$, and d: HTT $2500^{\circ} \mathrm{C}$ ).

Fig. 2 に $1000 \sim 2500^{\circ} \mathrm{C}$ で熱処理された炭素繊維の粉末 $\mathrm{X}$ 線回折図形を示す. 熱処理温度が高いものほど 002 回 折線のピークがシャープになり，また黒鈆の炭素網面回 折角度である $0.3354 \mathrm{~nm}$ を示す $26.6^{\circ}$ へと近づいていく 傾向がみられた. Fig.3 に熱処理温度による炭素繊維の 002 面の面間隔 $d_{002}$ の変化を示す. 特に $1500 \sim 2000^{\circ} \mathrm{C}$ の 間で, $d_{002}$ の顕著な減少がみられた. しかし, $2000^{\circ} \mathrm{C}$ 処理 のものでも $d_{002}$ は $0.344 \mathrm{~nm}$ と比較的大きく, 乱層構造炭 素の格子面間隔と同程度であった。 また，各炭素繊維の 結晶子サイズ $L_{c}(002), L_{a}(110)$ は, 熱処理温度が 1000〜 $1500^{\circ} \mathrm{C}$ の ので $2 \mathrm{~nm}, 2000 \sim 2500^{\circ} \mathrm{C}$ もので $3 \mathrm{~nm}$ と見積 もられた.このように本炭素繊維は, 高温の熱処理をお こなっても結晶子サイズは小さいままであった。このよ うに黒鉛結晶性が高くならないのは, 炭素繊維の炭素前 駆体である等方性ピッチは比較的サイズの小さい種々の 多環芳香族分子がランダムに配向している組織をとって おり, 高温の熱処理によっても結晶子が配向および成長 しにくい難黒鉛化性であるためと考えられる. 


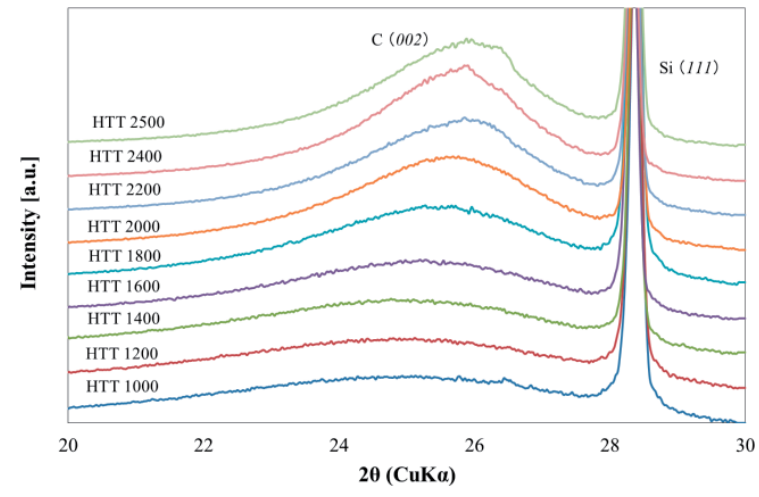

Fig. 2 Powder X-ray profiles of the isotropic pitch-based carbon fibers treated with various HTTs.

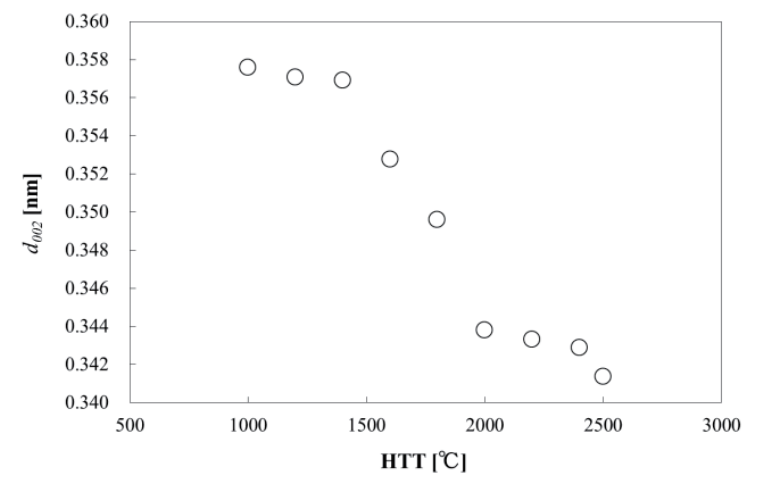

Fig. 3 Change in lattice constant $d_{002}$ of the isotropic pitch-based carbon fiber with HTT.

Fig. 4 に $1000 \sim 2500^{\circ} \mathrm{C}$ で熱処理された炭素繊維のラマ ンスペクトルを示す.すべての熱処理温度の炭素繊維サ ンプルについて $1360 \mathrm{~cm}^{-1}$ および $1580 \mathrm{~cm}^{-1}$ 付近にそれぞれ, 構造の乱れに起因するDバンドおよび黒鉛由来の振動モ ードに起因する $\mathrm{G}$ バンドがみられた. $1000^{\circ} \mathrm{C}$ おび $1500^{\circ} \mathrm{C}$ で熱処理した炭素繊維では，これらのピークが中 心で重なっており，ブロードなピークであった。これは 結晶構造が未発達であり ${ }^{11)}$, 炭素網面のエッジが多数存 在することに起因すると考えられる. 熱処理温度が $2000^{\circ} \mathrm{C}$ 処理のものではこれらのピークが分離し, シャー プな形状となった。ささらに $2500^{\circ} \mathrm{C}$ 処理のものでは結晶の 欠陥を示す D バンドが低くなる傾向がみられた. Fig. 5 に熱処理温度による $\mathrm{G}$ バンドの半值幅の変化を示す. $\mathrm{G}$ バンドの半值幅は，黒鉛構造の完全性の指標でありその 值が小さいほど黒鉛化度が高いとされている ${ }^{12)}$. 1800〜 $2000^{\circ} \mathrm{C}$ 処理の炭素繊維を境にして半值幅が大きく減少し ているのが認められた。この温度領域から黒鉛構造に近 づいているものと思われる。なお，黒鉛化度が天然黒鉛 に近いとされる高配向性熱分解黒鉛（HOPG）の G バン ドの半值幅が $14 \mathrm{~cm}^{-1}$ 程度であるとされるが, $2500^{\circ} \mathrm{C}$ 処理 のもので $\mathrm{G}$ バンドの半值幅が $44 \mathrm{~cm}^{-1}$ であり, 黒鉛化度が 低いことを示している.

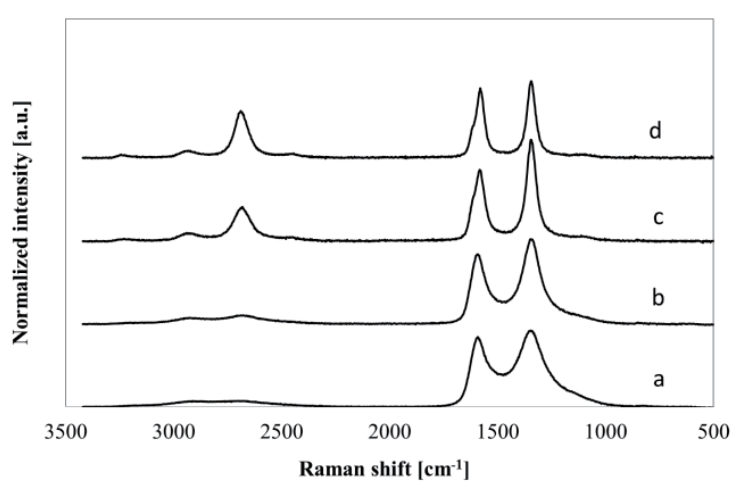

Fig. 4 Raman spectra of the isotropic pitch-based carbon fibers treated with different HTTs. (a: HTT $1000^{\circ} \mathrm{C}$, b: HTT $1500^{\circ} \mathrm{C}$, c: HTT $2000^{\circ} \mathrm{C}$, and d: HTT $2500^{\circ} \mathrm{C}$ )

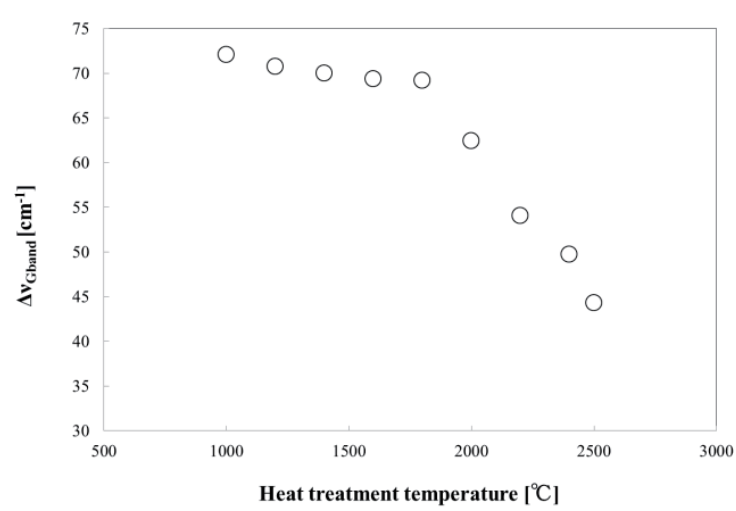

Fig. 5 Change in full width at half-maximum of G-band in Raman spectra of the isotropic pitch-based carbon fibers with HTT.

\section{$3 \cdot 2$ 炭素織維の空気酸化挙動}

Fig. 6 に TG 測定により得られた熱処理温度の異なる 炭素繊維の空気酸化による減量曲線を示寸. 熱処理温度 が高い炭素繊維ほど減量曲線が高温側へシフトしており, 重量減少の開始が認められる酸化開始温度は高くなった. また Table 1 に小沢法により算出した各炭素繊維の空気 酸化反応における活性化エネルギーを示す. 活性化エネ ルギーは，熱処理温度が高いものほど大きい值を示した。 同じ方法で天然黒鉛（鱗状黒鉛）の活性化エネルギーを 算出し, $203 \mathrm{~kJ} / \mathrm{mol}$ という值を得た。この值は $2500^{\circ} \mathrm{C} て ゙$ 熱 処理した炭素繊維は, $d_{002}$ や $\mathrm{G}$ バンドの半值幅からも天 然黒鉛に比べて，かなり低結晶性であるが，天然黒鉛と 同等の活性化エネルギーを示した. Fig.3に示すように炭 素繊維は熱処理温度が高くなるにつれて結晶の面間隔が 小さくなり，また, Fig.4および Fig.5 に示すように久陷が 減少していることが示唆されるが，より高温で熱処理さ れた炭素䋊維は酸化反応の活性点が少なくなっているた めに酸化耐久性が高くなったと考えられる. 


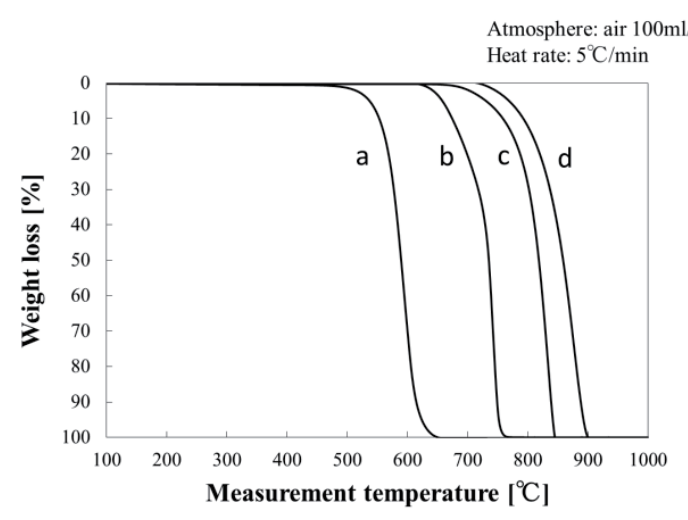

Fig. 6 Air-oxidation weight loss curves of the isotropic pitch-based carbon fibers treated with different HTTs obtained by thermogravimetry (TG). (a: HTT $1000^{\circ} \mathrm{C}, \mathrm{b}$ : HTT $1500^{\circ} \mathrm{C}$, c: HTT $2000^{\circ} \mathrm{C}$, and d: HTT $2500^{\circ} \mathrm{C}$ )

Table 1 Activation energies for air-oxidation of the isotropic pitch-based carbon fibers with different HTTs.

\begin{tabular}{cc}
\hline HTT $\left[{ }^{\circ} \mathrm{C}\right]$ & Activation Energy $[\mathrm{kJ} / \mathrm{mol}]$ \\
\hline 1000 & 102 \\
1500 & 138 \\
2000 & 155 \\
2500 & 205 \\
\hline
\end{tabular}

Fig. 7 に $1000 \sim 2500^{\circ} \mathrm{C}$ で熱処理された炭素繊維の酸化

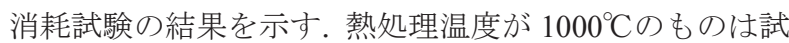
験開始から 1 時間後には $35 \%$ 重量減少がみられたが, $1500^{\circ} \mathrm{C}$ ものでは試験開始直後の減少がわずかであり， 約 2 時間後から重量減少の速度が 10 倍程度となった. $1000^{\circ} \mathrm{C}$ で熱処理された炭素㵶維は結晶性が非常に低く, 反応性の高い活性点が多く存在しており酸化が進行しや すいが， $1500^{\circ} \mathrm{C}$ で熱処理された炭素繊維では結晶構造が やや発達してその活性点が少なくなり酸化が進行しにく くなったものと考えられる。ここで酸化減量がさらに進 行する過程を考えてみると, 炭素繊維が酸素と反応し炭 素六角網面部分の炭素が除かれた場合，そこに新たな欠 陷が形成される，そしてその欠陥が反応の活性点となり， 加速的に酸化劣化が進行していくと考えられる.また熱 処理温度が $2000^{\circ} \mathrm{Cおよび} 2500^{\circ} \mathrm{C}$ のものは酸化減量が緩 やかであり，試験開始から 1 時閒後の重量減少率は $0.1 \% / \mathrm{h}$ 以下であったが，投入 3 時間後には試験開始時の 重量減少速度の 5 倍程度の速さとなった。

Fig. 8 に 10wt\%の酸化減量を施した炭素繊維のラマン スペクトルを酸化減量前のものと併せて示す. 熱処理温 度が $1000^{\circ} \mathrm{C}$ およ゙ $1500^{\circ} \mathrm{C}$ ののでは酸化前後でスペク

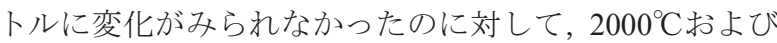
$2500^{\circ} \mathrm{C}$ のものについては酸化減量後の方が $\mathrm{D}$ バンドのピ 一クが大きくなる傾向がみられた。熱処理温度が低く結 晶性が非常に低いものでは, 反応の活性点が多く存在し ており，特に反応性の高い結晶子から消失していくため
に, エッジ炭素は増加せず, ラマンスペクトルに変化は みられないと考えられる。一方で熱処理温度が高く結晶 構造がやや発達したものでは活性点が少ないため, 酸化 反応は進行しにくく, 結晶の端面において少しずつ進行 し, エッジ炭素が増えることで, D バンドのピークが大 きくなったと考えられる ${ }^{13)}$.

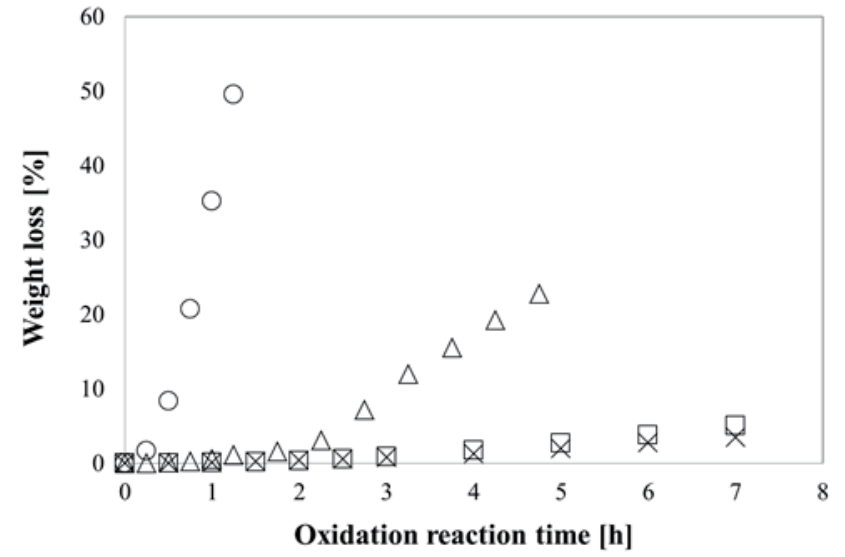

Fig. 7 Air-oxidation weight loss under $550^{\circ} \mathrm{C}$ of the isotropic pitch-based carbon fibers treated with different HTTs.

$\left(\bigcirc\right.$ HTT $1000^{\circ} \mathrm{C}, \triangle$ HTT $1500^{\circ} \mathrm{C}, \square$ HTT $2000^{\circ} \mathrm{C}$, and $\times$ HTT $\left.2500^{\circ} \mathrm{C}\right)$

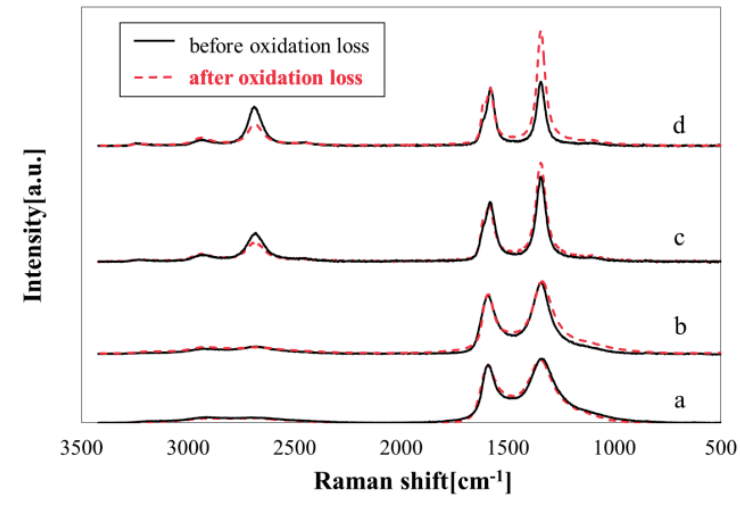

Fig. 8 Raman spectra of the isotropic pitch-based carbon fibers before and after 10wt $\%$ weight loss. (solid line: before oxidation loss, dotted line: after oxidation loss)

(a: HTT $1000^{\circ} \mathrm{C}$, b: HTT $1500^{\circ} \mathrm{C}$, c: HTT $2000^{\circ} \mathrm{C}$, and d: HTT $\left.2500^{\circ} \mathrm{C}\right)$

Table 2 に熱処理温度が $1000^{\circ} \mathrm{C}$ と $2500^{\circ} \mathrm{C}$ 炭素繊維の 空気酸化前後の比表面積および開気孔容積の変化を示す. 酸化前の炭素繊維はどちらの熱処理温度のものについて も開気孔が夕られなかったが，10wt\%の酸化減量を施し たものについては $1000^{\circ} \mathrm{C}$ 処理品が $2500^{\circ} \mathrm{C}$ 処理品に比べ て 10 倍以上の比表面積および開気孔容積となった。ま た酸化後の炭素繊維を SEM 観察したが, 外観や繊維径 に変化は見られなかった。 どちらも同じ $10 \mathrm{wt} \%$ の酸化減 量を施したにもかかわらず，このような違いがみられた のは, $2500^{\circ} \mathrm{C}$ 処理品では発生した開気孔が極めて小さく, 
吸着分子である窒素が開気孔内壁に吸着できなかったた めに低めの值となったと考えられる. $2500^{\circ} \mathrm{C} て ゙$ 熱処理さ れた炭素繊維では，反応の活性点が小さく，かつ少ない と考えられる。酸化によって新たな活性点が生じるが, もともとの活性点は大きく成長しないために, 生じた開 気孔は極めて小さいものではないかと推察される。この 開気孔の大きさは透過型電子顕微鏡（TEM）などによる 検証が今後必要である.

Table 2 Specific surface area and pore volume of the isotropic pith-based carbon fibers before (OL $0 \mathrm{wt} \%$ ) and after 10wt $\%$ oxidation loss (OL10wt\%).

\begin{tabular}{ccc}
\hline Sample & $\begin{array}{c}\text { Specific surface area } \\
{\left[\mathrm{m}^{2} / \mathrm{g}\right]}\end{array}$ & $\begin{array}{c}\text { Pore volume } \\
{\left[\mathrm{cm}^{3} / \mathrm{g}\right]}\end{array}$ \\
\hline HTT $1000^{\circ} \mathrm{C}(\mathrm{OL} \mathrm{0wt} \%)$ & 0.50 & 0.00 \\
HTT $2500^{\circ} \mathrm{C}(\mathrm{OL} 0 \mathrm{wt} \%)$ & 0.47 & 0.00 \\
HTT $1000^{\circ} \mathrm{C}(\mathrm{OL} 10 \mathrm{wt} \%)$ & 308 & 0.13 \\
HTT $2500^{\circ} \mathrm{C}(\mathrm{OL} 10 \mathrm{wt} \%)$ & 11.2 & 0.01 \\
\hline
\end{tabular}

\section{4 結}

本研究では，等方性ピッチ系炭素繊維の構造および空 気酸化挙動について調べた. その結果, 以下の結論を得 た。

1. 炭素纎維は, 熱処理温度が $1500 \sim 2000^{\circ} \mathrm{C}$ の間で, 黒鉛結晶の面間隔の顕著な減少がみられた。また 結晶子サイズ $L_{c}(002)$ および $L_{a}(110)$ は，2000〜 $2500^{\circ} \mathrm{C}$ で熱処理したものでも $3 \mathrm{~nm}$ 程度と小さく, 結晶子があまり発達していないことが認められた。

2. 熱処理温度が $1000^{\circ} \mathrm{C}$ と $1500^{\circ} \mathrm{C}$ の炭素繊維のラマン スペクトルにおける $\mathrm{D}$ バンドおよび $\mathrm{G}$ バンドはブ ロードなピークを示し，一方で熱処理温度が $2000^{\circ} \mathrm{C}$ おび $2500^{\circ} \mathrm{C}$ 処理のもののピークはシャー プな形状となった．熱処理温度が高くなるにつれ て，炭素纎維中の官能基を含めて欠陥が減少して いるものと考えられた. 熱処理温度が高くなるに つれて炭素繊維の空気酸化による重量減少の開始 温度および活性化エネルギーが高くなり，酸化耐 久性の向上が確認できた。

3. 炭素繊維を $550^{\circ} \mathrm{C}$ で空気中に一定時間保持したとき, 酸化反応はある時から減量の速さが 5〜10 倍とな って進行することが分かった。これは酸化進行に よって，炭素繊維中に新たな欠陷が生成され，そこ が活性点となって反応が加速的に進行するためと 考えられた。

4. 熱処理温度が高い炭素繊維では空気酸化によって ラマンスペクトルの D バンドが大きくなる傾向が みられた。活性点が少ないために酸化反応が進行 しにくく，結晶の端面において少しずつ進行して， エッジ炭素が生成されることによると考えられた.

5. $1000^{\circ} \mathrm{C}$ 処理の炭素繊維と異なり $2500^{\circ} \mathrm{C}$ 処理のもの は, 空気酸化後も比表面積および開気孔容積があ
まり大きくならなかった. $2500^{\circ} \mathrm{C}$ 処理のものは酸化 によって生じた開気孔が極めて小さく, 吸着分子 である窒素が開気孔内壁に吸着できなかったため と考えられた。

以上のことから, 熱処理温度が高い炭素繊維は結晶の 欠陥が少なく, 空気酸化に対する耐久性が高いことが判 明した．そのため炭素繊維が高温炉用断熱材に使用され る場合, 熱処理温度の高いものを使用することが耐久性 の向上に有効であると考えられる.

\section{参考文献}

1) S. Otani and A. Oya, "Carbon fiber nyumon" pp.74-80 (1983) Ohmu-sha.

2) Y. Matsumura, "Karyuuhou-niyoru-picchi-keitansoseni-no-seizou", Proceedings of the Tansosogenryou-no-yuuko-riyou V, pp.173-181 (1987) CPC Kenkyu-kai.

3) M. Furukawa and T. Ito, "Kyokujo-no-picchi-keitansoseni-no-tokusei”, REINFORCED PLASTICS, Vol.34, No.3, pp.89-93 (1988).

4) K. Okuda, "Picchi-kei-tansoseni-no-genjyou-to- kadai", Proceedings of the 23rd Composite material Seminar, pp.9-18 (2010) JCMA.

5) T. Sogabe, "Touhousei-picchi-kei-tansoseni-notokuchou- to-hottzohn-you-dan-netsuzai”, Proceedings of the Tanso-zairyou-no-kenkyuukaihatsu-doukou, pp.125-134 (2014) CPC Kenkyu-kai.

6) A. Mabuchi, "Picchi-kei-tansoseni-no-genjyou-tokadai", Proceedings of the 27th Composite material Seminar, pp.9-18 (2014) JCMA.

7) N. Iwashita, C.R. Park, H. Fujimoto, M. Shiraishi and M. Inagaki, "Specification for a standard procedure of X-ray diffraction measurements on carbon materials", Carbon Vol.42, pp.701-714 (2004).

8) The 117 Committee of the Japan Society for the Promotion of Science, "Procedure for the measurements of lattice parameters and crystallite sizes of carbon materials by X-ray diffraction" TANSO, Vol.2006, No.221, pp.52-60 (2006).

9) H. Fujimoto, "Analysis of x-ray diffraction pattern of carbon by the profile fitting method" TANSO Vol.2003, No.206, pp.2-6 (2003).

10) T. Ozawa and H. Yoshida, "Saishin-netsubunseki", pp.88-107 (2005) Kodansha-scientific.

11) K. Kojima, A. Oya, K. Maruyama and Y. Yamada, "Carbonization and graphitization behavior of decacyclene" Carbon, Vol.35, pp.253-258 (1997).

12) G. Katagiri, "Raman spectroscopy of graphite and carbon materials and its recent application" TANSO, Vol.1996, No.175, pp.304-313 (1996).

13) L.G.Cancado, K.Takai, T.Enoki, M.Endo, Y.A.Kim, 
H.Mizusaki, A.Jorio, L.N.Coelho, R.Magalhaes, M.A.Pienta, "General equation for the determination of the crystallite size $L_{a}$ of nanographite by raman spectroscopy" Applied physical letter, Vol.88, pp.163016/1-163016/3 (2006). 